\title{
OXYGEN LIMITATION FAVORS THE PRODUCTION OF PROTEIN WITH ANTIMICROBIAL ACTIVITY IN PSEUDOALTEROMONAS SP
}

\author{
Ruth López $^{1 *}$, Víctor Monteón ${ }^{1}$, Ernesto Chan ${ }^{1}$, Rubí Montejo ${ }^{1}$, Manuel Chan ${ }^{2}$ \\ ${ }^{1}$ Centro de Investigaciones Biomédicas, Universidad Autónoma de Campeche, Av. Patricio Trueba s/n Col. Lindavista C.P.24090, \\ Campeche, México; ${ }^{2}$ Centro de Investigaciones en Corrosión, Universidad Autónoma de Campeche, Av. López Portillo s/n Col. \\ Buenavista C.P 24030, Campeche, México.
}

Submitted: July 29, 2011; Returned to authors for corrections: August 29, 2011; Approved: June 07, 2012.

\begin{abstract}
This study examined the effect of dissolved oxygen concentration on the production of biomass and metabolites with antimicrobial activity of Pseudoalteromonas sp cultured at $0,150,250$, or 450 revolutions per minute (rev. $\mathrm{min}^{-1}$ ). Dissolved oxygen (D.O) was monitored during the fermentation process, biomass was quantified by dry weight, and antimicrobial activity was assessed using the disk diffusion method.

The bacterium Pseudoalteromonas reached similar concentration of biomass under all experimental agitation conditions, whereas antimicrobial activity was detected at 0 and $150 \mathrm{rev} . \mathrm{min}^{-1}$ registering $\quad 0 \%$ and $12 \%$ of D.O respectively corresponding to microaerophilic conditions. Antibiotic activity was severely diminished when D.O was above $20 \%$ of saturation; this corresponded to 250 or 450 rev. min $^{-1}$. SDS-PAGE electrophoresis revealed a protein with a molecular weight of approximately 80 kilodaltons $(\mathrm{kDa})$ with antimicrobial activity.

Pseudoalteromonas is capable of growing under oxic and microaerophilic conditions but the metabolites with antimicrobial activity are induced under microaerophilic conditions.

The current opinion is that Pseudoalteromonas are aerobic organisms; we provide additional information on the amount of dissolved oxygen during the fermentation process and its effect on antimicrobial activity.
\end{abstract}

Key words: Pseudoalteromonas, oxygen limitation, agitation rate, microaerophilic

\section{INTRODUCTION}

Nowadays, many drugs obtained from microorganisms are used. Bacteria of the genus Pseudoalteromonas are among marine microorganisms that produce bioactive substances, such as anti-inflammatory, extracellular enzymes, polymers, etc. $(14,19)$. The genus Pseudoalteromonas produces a wide variety of metabolites that inhibit the growth of other microorganisms including pathogens such as Staphylococcus aureus (MRS) or Pseudomonas aeruginosa (4, 5, 12). Among these compounds are several soluble substances of low molecular weight, such as pentabromopseudilin, and antibiotic substances of high molecular weight of protein nature $(4,17)$. This genus requires organic factors and depends on sodium ions for growth, it is strictly aerobic non-fermentative $(13,15)$, and inhabits coastal waters, open sea, marine sediment, and

*Corresponding Author. Mailing address: Centro de Investigaciones Biomédicas, Universidad Autónoma de Campeche, Av. Patricio Trueba s/n Col. Lindavista C.P.24090, Campeche, México.; Tel/Fax.: (+52 981) 813-0176.; E-mail: ruthloalcantar@yahoo.com.mx / dzinup@hotmail.com 
various surfaces of marine organisms $(10,16)$.

In aerobic bioprocesses, oxygen is one of the factors that greatly affect the growth of most microorganisms due to the low solubility in aqueous solution, and aerobic processes can become a critical factor for the production of specific metabolites. Oxygen can be supplied continuously by agitation to the culture medium and the dissolved oxygen concentration controls rely on regulation of agitation speeds (11). Studies in terrestrial and marine organisms have shown that oxygen largely determines the production of biomass and secondary metabolites; for example, specific growth rate of the marine bacterium Vibrio harveyi increased with agitation (7). Agitation of Pseudoalteromonas luteoviolacea at different intensities did not affect biomass but influenced the production of violacein (26). On the other hand, Pham et al. (21) observed in cultures of Bacillus sp 1-1018 that aeration had no effect on the maximum value of biomass.

But in other cases, the effect of increasing the oxygen transfer rate can significantly reduce the cellular yield, as reported for Bacillus licheniformis (8) or, to the contrary, it can stimulate cellular yield of Xenorhabdus nematophila (25). However, in cultures of microaerophilic Campylobacter jejuni and Pseudomonas aeruginosa PA01 dissolved oxygen (D.O) between 3 and 15\% was optimal for growth, but above this value it had a negative effect on cellular growth $(20,22,24)$.

In previous studies, we isolated from marine sediment of the coast of Campeche, Mexico, a bacterium identified as Pseudoalteromonas sp., which showed antimicrobial activity against pathogenic bacteria (5). The antimicrobial activity occurred in the stationary phase. In this study, we further investigated the effect of dissolved oxygen concentration on biomass production and antibacterial activity of the marine bacterium Pseudoalteromonas sp.

\section{MATERIALS AND METHODS}

\section{Microorganism}

The bacterium used in this study was obtained from sediment samples of the Gulf of Mexico, Campeche as described previously (5). The strain was identified on molecular 16S rRNA gene sequence -based as Pseudoalteromonas sp., and the antimicrobial activity of biomass against human pathogens was reported (5).

\section{Culture conditions}

A pre-culture was prepared by inoculating $0.1 \mathrm{~mL}$ of bacterial Pseudoalteromonas sp. from our frozen stock to 25 $\mathrm{mL}$ of medium growth in a $125 \mathrm{~mL}$ flask and left to grow for $24 \mathrm{~h}$ at $28{ }^{\circ} \mathrm{C}$ on an orbital shaker at $150 \mathrm{rev} \cdot \mathrm{min}^{-1}$. The YPG (yeast-peptone-glucose) growth medium was prepared as follows $\left(\mathrm{g} \mathrm{L}^{-1}\right)$ : yeast extract, 4.0; peptone, 5.0; glucose, 10; iron citrate, 0.001. All components were dissolved in filtered natural seawater and adjusted to $\mathrm{pH}$ 7.0. This medium was selected because it was found the best on experimental assays and to enhance growth and antimicrobial activity of Pseudoalteromonas.

\section{Effect of agitation}

Erlenmeyer flasks of $250 \mathrm{~mL}$ with $50 \mathrm{~mL}$ growth medium mentioned before were inoculated with $5 \%$ of pre-culture cell suspension. The culture was subjected to different agitation intensities $\left(0,150,250\right.$, or $\left.450 \mathrm{rev} \mathrm{min}^{-1}\right)$ and incubated during $72 \mathrm{~h}$ at $28{ }^{\circ} \mathrm{C}$. The dissolved oxygen was monitored during fermentation and it was measured by a digital D.O meter (The M300 O2 transmitter, Mettler Toledo) and Mettler Toledo probe. Calibration was done according to manufacturer's instruction.

\section{Determination of cell dry weight}

A $25 \mathrm{~mL}$ amount of cultured marine bacteria was filtered through GSWP 0.22- $\mu \mathrm{m}$-pore-size Millipore membranes under vacuum; the mass retained on the filter was washed with 25 $\mathrm{mL}$ of sterile natural seawater. The cells were dried in a microwave oven $(780 \mathrm{~W})$ with carousel set to $60 \%$ of the maximum power in successive cycles of $1 \mathrm{~min}$ to its constant weight. Constant weight was considered when the value does 
not change after three consecutive weighing. Every determination from each treatment was performed thrice and the corresponding averages were reported.

\section{Crude extract}

Marine bacterial cells were separated from the spent broth by centrifugation (at $3000 \mathrm{~g}$ for $15 \mathrm{~min}$ at $4{ }^{\circ} \mathrm{C}$ ) and washed with sterile natural seawater twice. Two grams of biomass were resuspended in $10 \mathrm{~mL}$ of PBS and sonicated. After, nine volumes of cold $100 \%$ ethanol were added to one volume of sonicated solution, mixed, and kept for at least $10 \mathrm{~min}$ at -20 ${ }^{\circ} \mathrm{C}$. The mix was centrifuged for $15 \mathrm{~min}$ at $4{ }^{\circ} \mathrm{C}$ at $15000 \mathrm{~g}$. The pellet retained was washed with cold $90 \%$ ethanol and dried (by inversion on tissue paper). The dried sample was resuspended in $50 \mathrm{mM}$ PBS, $\mathrm{pH} 7.0$, to adjust protein concentration to $4.0 \mathrm{mg} \mathrm{mL}^{-1}$. This crude extract was used to evaluate antimicrobial activity against pathogen bacteria using the conventional diffusion plate method.

\section{Determination of antimicrobial activity}

Antibacterial activity of crude extract was tested by the standard disk diffusion (Kirby-Bauer) method $(2,23)$, against clinical pathogens which included: Gram positive bacteria Staphylococcus aureus ATCC 25923 (a), Staphylococcus aureus (b) clinical isolates sensitive to ampicillin (AM), ceftazidime (CAZ), cefataxime (CXM), gentamicin (GM) and Staphylococcus aureus (c) MRSA clinical isolate resistant to AM, GM, CAZ, and Gram negative bacteria such as Escherichia coli ATCC 25922 (d) and Pseudomonas aeruginosa (e) clinical isolate resistant to cefataxime (CTX), amikacin (AN). Paper disks impregnated with $20 \mu \mathrm{L}$ of crude extracts were used for the antimicrobial activity assay using the conventional diffusion plate method. Clear zones of inhibition around the disks indicate antibacterial activity, which was measured after $24 \mathrm{~h}$ of incubation at $37^{\circ} \mathrm{C}$. Ceftazidime and vancomycin were used as positive controls in the each plates and $50 \mathrm{mM}$ PBS as negative control.
The specific activity of the antimicrobial substance was determined semiquantitatively by the procedure of Ballester et al. (1) with minor modifications. Vancomycin and ceftazidime were used as antibiotics reference against Gram positive or Gram negative pathogens respectively. One unit of antimicrobial activity was defined as the quantity of the active substance giving rise to the same level of inhibition as $1 \mu \mathrm{g}$ of vancomycin or $2 \mu \mathrm{g}$ of ceftazidime did. Specific activity $(\mathrm{Yp} / \mathrm{x})$ was the number of units per milligram (dry weight cell). The determinations from each treatment were performed at least thrice and the averages are reported.

\section{Polyacrylamide gel electrophoresis}

Sodium dodecyl sulfate polyacrylamide gel electrophoresis (SDS-PAGE) was performed with 4\% acrylamide in the stacking gel and $12 \%$ acrylamide in the separating gel. The running buffer was Tris- glycine and $0.1 \%$ $\mathrm{SDS}, \mathrm{pH}$ 8.3. The crude extract was mixed with half volume of the tray buffer (Tris-HCl, pH 6.8, 15\% glycerol and 0.075\% bromophenol blue). After electrophoresis, the gel was fixed and stained with isopropanol-water-acetic acid (2.5:6.5:1) containing 0.05\% Coomassie Brillant Blue for $2 \mathrm{~h}$ and then distained with methanol-water-acetic acid (4.5:3.5:2) solution. The gel was submerged in $10 \%$ acetic acid for $15 \mathrm{~min}$. The antibacterial activity was assayed by bioautography. The gel was cut into strips, washed and placed on Mueller Hinton plates previously inoculated with $S$ aureus ATCC 25923. Vancomycin was used as positive control and $50 \mathrm{mM}$ PBS was used as negative control. After $24 \mathrm{~h}$ of incubation at $37{ }^{\circ} \mathrm{C}$, the migration of active substance was evidenced by of the growth inhibition zone around the strips (3).

\section{Statistics}

To establish statistical differences among groups we used one-way ANOVA. Kruskal Wallis and the Mann Whitney test for comparison between two groups by means of the GrapPad PRISMA4 software. 


\section{RESULTS}

\section{Effect of Agitation rate on biomass production}

The final concentration of biomass produced at $72 \mathrm{~h}$ and $28^{\circ} \mathrm{C}$ of incubation of the marine bacterium Pseudoalteromonas sp under different agitation conditions was between $5.5-6 \mathrm{mg} \mathrm{mL} \mathrm{mL}^{-1}$ (Fig. 1). The highest biomass production was at $450 \mathrm{rev} \mathrm{min}^{-1}$ and the lowest at $150 \mathrm{rev} \mathrm{min}$

1 . However, there was no statistical difference in biomass, in spite that D.O varied from 0 to $44 \%$ of saturation. These data suggest that agitation rate had not effect on biomass production.

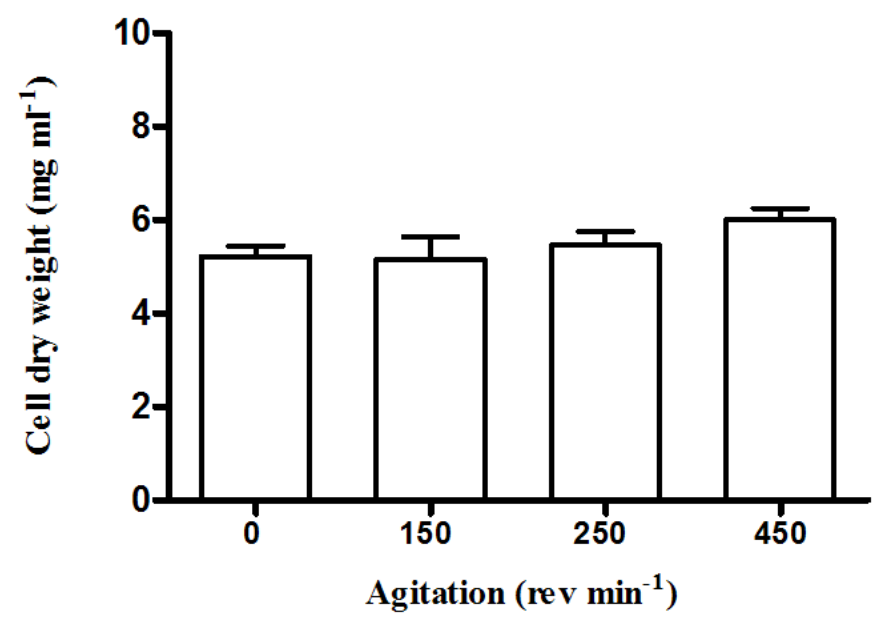

Figure 1. Biomass production of Pseudoalteromonas sp after $72 \mathrm{~h}$ of culture at different agitation intensities.

\section{Effect of Agitation rate on antimicrobial activity}

As shown in Figure 2, the specific activity $(\mathrm{Yp} / \mathrm{x})$ of the antimicrobial substance was detected only when the marine bacterium grew in static conditions at $150 \mathrm{rev} \mathrm{min}^{-1}$; but higher agitation suppressed the antibacterial activity. The D.O at static and $150 \mathrm{rev} \mathrm{min}^{-1}$ corresponded to 0 and $12 \%$ saturation, respectively, whereas the D.O ranged from 30 to $44 \%$ of saturation at 250 and $450 \mathrm{rev} \min ^{-1}$ (Fig. 3). These data suggested that the intensity of agitation, which involves controlling the amount of oxygen dissolved in the medium, was a factor affecting the regulation of antimicrobial activity.

Furthermore, there were no differences of antibacterial profiles against the five pathogenic strains.

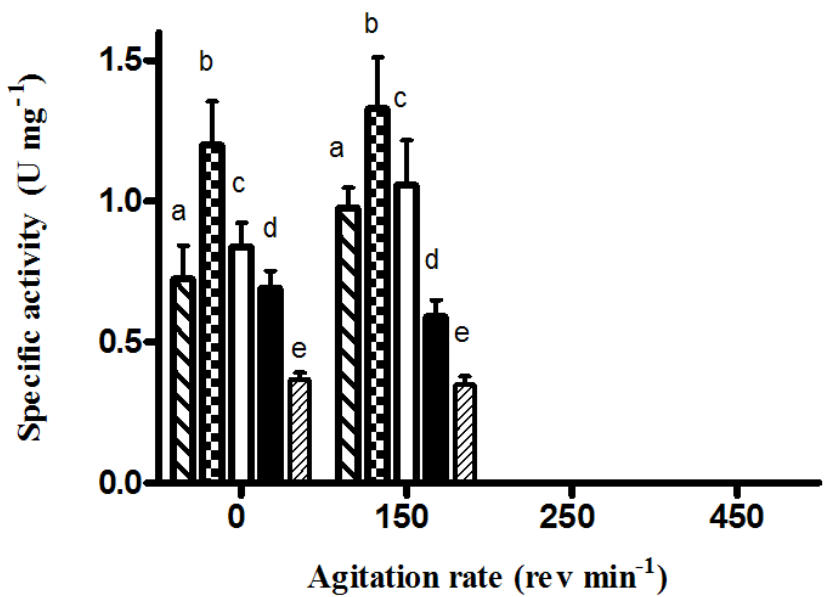

Figure 2. Specific activity of the antimicrobial substance of crude extract of Pseudoalteromonas sp under different agitation intensities. Values are expressed as U/mg, against

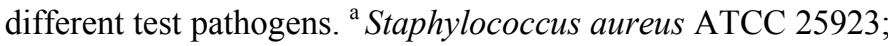

b Staphylococcus aureus clinical isolated sensible to AM, CAZ,CXM, GM; ' Staphylococcus aureus (MRSA) clinical isolated resistant to AM, GM, CAZ; ${ }^{\mathrm{d}}$ Escherichia coli ATCC 25922; ${ }^{\mathrm{C}}$ P.aeruginosa clinical isolate resistant to cefataxime (CTX), amikacin (AN)

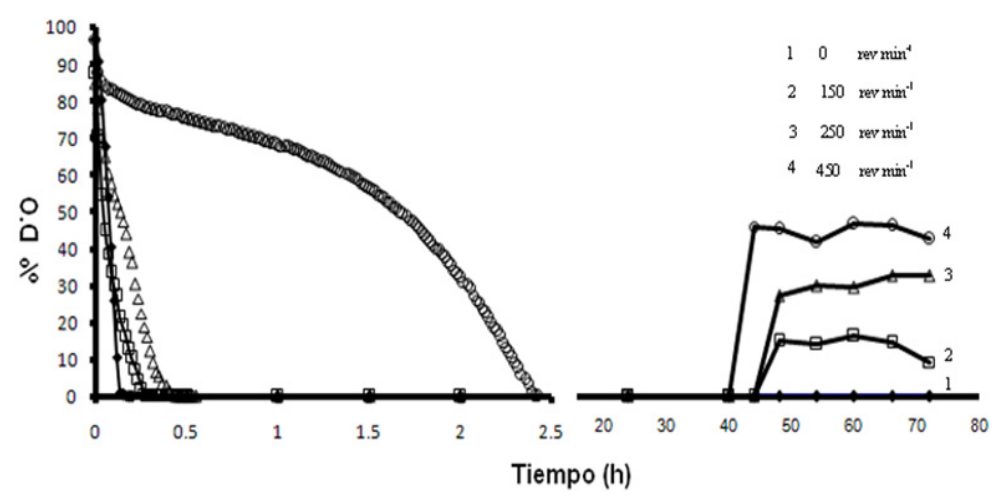

Figure 3. Profiles of dissolved oxygen concentration ( $\%$ saturation) in batch fermentation by Pseudoalteromonas $\mathrm{sp}$ under different agitation intensities in rev $\mathrm{min}^{-1}$ 


\section{Dissolved oxygen concentration in the fermentation process}

The concentration of D.O was monitored during fermentation when the marine bacterium grew in cultures agitated at 0,150 , 250 , or $450 \mathrm{rev} \min ^{-1}$ (Fig. 3). The oxygen was drastically consumed since the first minutes of the fermentation process. Surprisingly, the cultures were strongly limited in oxygen after 15 , 27, 42, and $140 \mathrm{~min}$ of incubation and until approximately $46 \mathrm{~h}$. After this point of incubation, an increase in D.O occurred in the cultures agitated at 150, 250, and $450 \mathrm{rev} \mathrm{min}^{-1}$ (approximately 15, 30 , and $44 \%$ of saturation, respectively), and persisted until the end of the fermentation process. Except for the static culture in which the D.O was $0 \%$ of saturation along the whole process.

\section{Antibacterial protein}

The SDS-PAGE protein profiles of crude extract of the sonicated biomass of Pseudoalteromonas sp. showed the presence of one band of approximately $80 \mathrm{kDa}$ and another unresolved bands of less than $20 \mathrm{kDa}$ (Fig. 4A). The bioautography revealed an area of strong growth inhibition at the height of the band of 80 $\mathrm{kDa}$ when it was incubated in Petri dishes inoculated with the control strain S. aureus ATCC 25923 (Fig. 4B), suggesting that the compound with antimicrobial activity is a protein of high molecular weight.

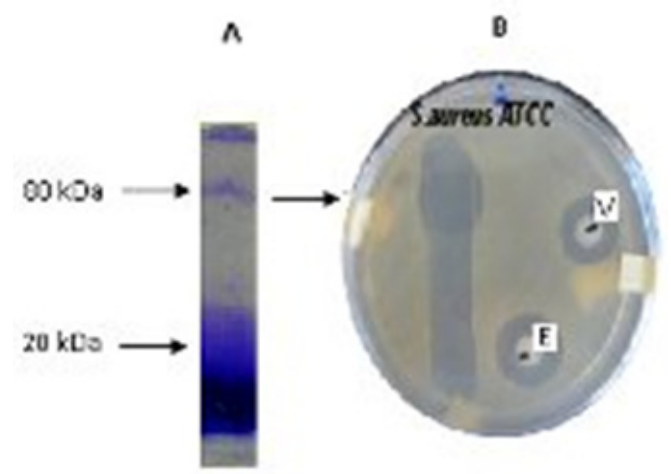

Figure 4. (A) SDS-PAGE electrophoresis of crude extract of Pseudoalteromonas sp and (B) gel developed by direct bioautography against S. aureus ATCC 25923 showing a single inhibitory zone. Clear zones of inhibition around the disks and strip of gel indicate antibacterial activity, (V) refers to disk impregnated with positive control vancomycin; (E) refers to disk impregnated with crude extract. The arrows show the position of molecular mass in kilodaltons.

\section{DISCUSSION}

In aerobic fermentation, the oxygen transfer rate from the gas phase to the culture medium is a key factor that strongly influences biomass productivity and diverse valuable metabolites. In this study, we found that different agitation conditions in Pseudoalteromonas sp. culture did not affect the amount of biomass produced at the end of fermentation (Fig. 1) even when bacteria grew at $600 \mathrm{rev} \min ^{-1}\left(5.2 \mathrm{mg} \mathrm{mL}^{-1}\right)$ in a bioreactor (data not shown). The D.O varied from 0 to $44 \%$ of saturation, but biomass was very similar for all conditions $\left(5.5-6 \mathrm{mg} \mathrm{mL}^{-1}\right)$. These data suggest that D.O had no effect on the production of biomass. Similar data on the effect of agitation on biomass production of Pseudoalteromonas luteoviolacea were reported by Yang et al. (26), although in their study did not determine the effect of D.O in the fermentation medium.

On the other hand, it was found that the oxygen demand was higher than the oxygen transfer rate during the logarithmic phase of growth in all tested conditions of agitation. Under these growth conditions, the D.O dropped dramatically to $0 \%$ from the first minutes of incubation until about $45 \mathrm{~h}$ regardless of the intensity of agitation, indicating that oxygen demand increases with agitation speed but it does not imply biomass increases. Probably the genus Pseudoalteromonas produces the highest concentration of extracellular polymeric substances and the lowest number of cells at low agitation, inversely to aerobic conditions from high speed. In all these experimental conditions the biomass was constant. Gao et al. (9) observed in a microbial community a link between generation of extracellular polymeric substances (EPS) and low D.O (approximately $10 \%$ of saturation).

The antimicrobial activity is produced in the stationary phase of growth in static conditions or $150 \mathrm{rev} \mathrm{min}^{-1}$ (from 0.4 to 1.3 $\mathrm{U} / \mathrm{mg}$ ). But antimicrobial activity was lost when the culture was agitated at 250 or $450 \mathrm{rev} \mathrm{min}^{-1}$ (Fig. 2) and the D.O was greater than 20\% saturation (Fig. 3). This finding indicates that low tension of oxygen (less than $15 \%$ of saturation) is necessary to induce the production of antimicrobial substances; probably, this is a stress response that may facilitate ecological competition and assimilation of nitrogen sources (12), promoting threshold concentration of quorum sensing signals involved in biofilm 
formation and production of toxins (6).

Similar results have been described in other organisms such as Pseudomonas aeruginosa strain PA01 and psychrotropic bacterium RT102, where microaerophilic conditions do favor the production of the virulence factors and the antibacterial violet pigment, respectively $(18,22)$. It has been accepted that microaerophilic conditions range between 3 and $15 \%$ of oxygen saturation (24).

Yang et al. (26) suggested that the decrease of antibacterial pigment produced by Pseudoalteromonas luteoviolacea was due to the negative impact of shear stress on biofilm formation and high agitation and but not due to increased D.O in the medium during fermentation. However, our results show that the antimicrobial activity is influenced by agitation or more specifically by D.O higher than $20 \%$ saturation, because at $12 \%$ saturation we observed antimicrobial activity. Thus, we agree with the microaerophilic hypothesis.

The antimicrobial compound according to SDS-PAGE and bioautography indicates a protein nature with high molecular weight of approximately $80 \mathrm{kDa}$ (Figs. 4A and 4B) produced by Pseudoalteromonas, the active substance was evidenced by of the growth inhibition zone (3). In this line of evidence, Bowman (4) mentioned that several species of Pseudoalteromonas secreted soluble proteins and other molecules with high molecular weight with antibacterial activity.

In conclusion, Pseudoalteromonas produces an antimicrobial protein of a molecular weight of approximately $80 \mathrm{kDa}$ and its activity can be induced under microaerophilic condition, but the bacterium is capable of growing under oxic and microaerophilic conditions.

\section{ACKNOWLEDGEMENTS}

The authors thank Fondo Mixto CONACYT-Campeche FOMIX- 31692 for financial support and Yareni Monteón for her technical assistance.

\section{REFERENCES}

1. Ballester, M.; Ballester, J.M.; Belaich, J.P. (1977). Isolation and characterization of a high molecular weight antibiotic produced by a marine bacterium. Microb. Ecol., 3, 289-303.

2. Bauer, A.W.; Perry, D.M.; Kirby, W.M.M. (1959). Single-Disk antibiotic-sensitivity testing of Staphylococci. Arch Intern Med., 104, 220-241.

3. Betina, V. (1973). Bioautography in paper and thin-layer chromatography and its scope in the antibiotic field. J. Chromatog., 78, 41-51.

4. Bowman, J.P. (2007). Bioactive compounds synthetic capacity and ecological significance of marine bacterial genus Pseudoalteromonas. Mar Drugs., 5, 220-241.

5. Cetina, A.; Matos, A.; Garma, G.; Barba, H.; Váquez, R.; ZepedaRodríguez, A.; Jay, D.; Monteón, V.; Lopez-A, R. (2010). Antimicrobial activity of marine bacteria isolated from Gulf of Mexico. Rev. Peru. Biol., 17, 231-236.

6. Dobretsov, S.; Teplitski, M.; Paul, V. (2009). Mini-review: quorum sensing in the marine environment and its relationship to biofouling. Biofouling. , 25, 413-427.

7. Estrada-Badillo, C.; Márquez-Rocha, F.J. (2003). Effect of agitation rate on biomass and protease production by a marine bacterium Vibrio harveyi cultured in a fermentor. World J. Microbiol. Biotechnol., 19, 129-133.

8. Flickinger, M.C.; Perlman, D. (1979). Application of oxygen-enriched aeration in the production of bacitracin by Bacillus Licheniformis. Antimicrob. Agents Chemother., 15, 282-293.

9. Gao, D.W.; Fu, Y.; Tao, Y.; Li, X-x.; Xing, M.; Gao, X-h.; Ren, N-g. (2011). Linking microbial community structure to membrane biofouling associated with varying dissolved oxygen concentration. Biores. Technol., 102, 5626-5633.

10. Gauthier, G.; Gauthier, M.; Christen, R. (1995). Phylogenetic analysis of the genera Alteromonas, Shewanella, and Moritella using genes coding for small-subunit rRNA sequences and division of the genus Alteromonas into two genera, Alteromonas (Emended) and Pseudoalteromonas gen. nov., and twelve new species combinations. Int. J. Sys. Bacteriol., 45, 755-761.

11. García-Ochoa, F.; Gómez, E. (2009). Bioractor scale-up and oxygen transfer rate in microbial process: an overview. Biotechnol. Adv., 27, 153-176.

12. Gómez, D.; Espinosa, E.; Bertazzo, M.; Lucas-Elío, P.; Solano, P.; Sanchez-Amat, A. (2008). The macromolecule with antimicrobial activity synthesized by Pseudoalteromonas luteoviolacea strain is an Lamino acid oxidase. Appl. Microbiol. Biotechnol., 79, 925-930.

13. Holmstrom, C.; James, S.; Neilan B.A.; White, D.C.; Kjelleberg, S. 
(1998). Pseudoalteromonas tunicate sp.nov. a bacterium that produces antifouling agents. Int. J. Sys. Bacteriol., 48, 1205-1212.

14. Holmstrom, C.; Kjelleberg, S. (1999). Marine Pseudoalteromonas species are associated with higher organisms and produce biologically active extracellular agents. FEMS Microbiol. Ecol., 30, 285-293.

15. Ivanova, E.P.; Shevchenko, L.S.; Sawabe, T.; Lysenko, A.M.; Svetashev, V.I.; Gorshkova, N.M.; Satomi, M.; Christen, R.; Mikhailov, V.V. (2002). Pseudoalteromonas maricaloris sp.nov, isolated from an Australian sponge, and reclassification of Pseudoalteromonas aurantia NCIMB as Pseudoalteromonas flavipulchra sp.nov. Int. J. Syst. Evol. Microbiol., 52, 263-271.

16. Ivanova, E.P.; Gorshkova, N.M.; Zhukova, N.V.; Lsenko, A.M.; Zelepuga, E.A.; Prokofeva, N.G.; Mikhailov, V.V.; Nicolau, D.V.; Christen, R. (2004). Characterization of Pseudoalteromonas distinctalike sea-water isolates and description of Pseudoalteromonas aliena sp.nov. Int. J. Syst. Evol. Microbiol., 54, 1431-1437.

17. McCarthy, S.A.; Johnson, R.M.; Kakimoto, D. (1994). Characterization of an antibiotic produced by Alteromonas luteoviolacea Gauthier 1982, 85 isolated from Kinko Bay, Japan. J. Appl. Bacteriol., 77, 426-432.

18. Nakamura, Y.; Asada, C.; Sawada, T. (2003). Production of antibacterial violet pigment by psychrotropic bacterium RT102 strain. Biotechnol. Bioprocess. Eng., 8, 37-40.

19. Oh, Ch.; Nikapitiya, Ch.; Lee, Y.; Whang, I.; Kang, D.; Heo, S.; Choi, U.; Lee, J. (2010). Molecular cloning, characterization and enzymatic properties of a novel beta-agarase from a marine isolate Pseudoalteromonas sp. AG52. Braz. J. Microbiol., 41, 876-889.

20. Perez, L.R.R.; Costa, M.C.N.; Freitas, A.L.P.; Barth, A.L. (2011). Evaluation of biofilm production by Pseudomonas aeruginosa isolates recovered from cystic fibrosis and non-cystic fibrosis patients. Braz. J. Microbiol., 42, 476-479.

21. Pham, P.L.; Strehaiano, P.; Taillandier, P. (1998). Effect of aeration on xylanase production by Bacillus sp. 1-1018. Bioproc. Eng., 1, 41-43.

22. Sabra, W.; Kim, E.; Zeng, A. (2002). Physiological responses of Pseudomonas aeruginosa PA01 to oxidative stress in controlled microaerobic and aerobic cultures. Microbiology., 148, 3195-3202.

23. Valgas, C.; Machado de Souza, S.; Smania, E.F.A.; Smania, A. (2007). Screening methods to determine antibacterial activity of natural products. Braz. J. Microbiol., 38, 369-380.

24. Wainwright, L.M.; Elvers, K.T.; Park, F.S.; Poole, R.K. (2005). A truncated haemoglobin implicated in oxygen metabolism by microaerophilic food-borne pathogen Campylobacter jejuni. Microbiology., 151, 4079-4091.

25. Wang, Y-H.; Zhang, X. (2007). Influence of agitation and aeration on growth and antibiotic production by Xenorhabdus nematophila. World. J. Microbiol. Biotechnol., 23, 221-227.

26. Yang, L.H.; Xiong, H.; Lee, O.O.; Qi, S.H.; Qian, P.Y. (2007). Effect of agitation on violacein production in Pseudoalteomonas luteovolacea isolated from a marine sponge. Leet. Appl. Microbiol., 44, 625-630. 